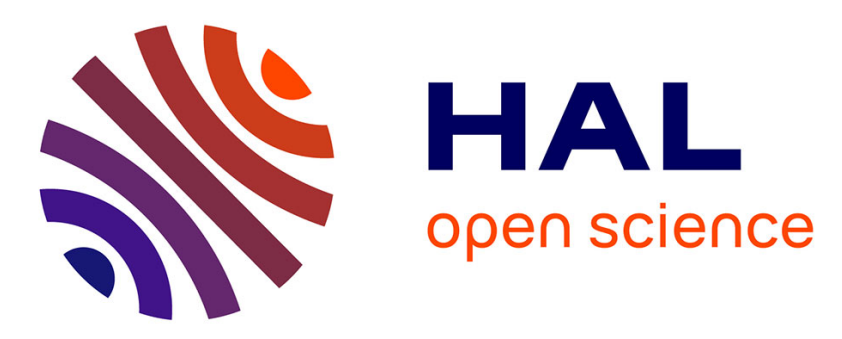

\title{
Synthesis of Te-Bi core-shell nanowires by two-step electrodeposition in ionic liquids
}

Laura Thiebaud, Sophie Legeai, Jaafar Ghanbaja, Nicolas Stein

\section{To cite this version:}

Laura Thiebaud, Sophie Legeai, Jaafar Ghanbaja, Nicolas Stein. Synthesis of Te-Bi core-shell nanowires by two-step electrodeposition in ionic liquids. Electrochemistry Communications, 2018, 86, pp.30 - 33. 10.1016/j.elecom.2017.11.010 . hal-01840644

\section{HAL Id: hal-01840644 \\ https://hal.univ-lorraine.fr/hal-01840644}

Submitted on 4 Oct 2021

HAL is a multi-disciplinary open access archive for the deposit and dissemination of scientific research documents, whether they are published or not. The documents may come from teaching and research institutions in France or abroad, or from public or private research centers.
L'archive ouverte pluridisciplinaire HAL, est destinée au dépôt et à la diffusion de documents scientifiques de niveau recherche, publiés ou non, émanant des établissements d'enseignement et de recherche français ou étrangers, des laboratoires publics ou privés. 


\section{Synthesis of Te-Bi core-shell nanowires by two-step electrodeposition in ionic liquids}

\section{Laura Thiebaud $^{1,2}$, Sophie Legeai*1, Jaafar Ghanbaja ${ }^{3}$, Nicolas Stein ${ }^{1}$}

${ }^{1}$ Institut Jean Lamour, UMR CNRS 7198, Université de Lorraine, 1 boulevard Arago, 57078 Metz Cedex 3, France

${ }^{2}$ present address EMPA, Laboratory for Mechanics of Materials and Nanostructures, Swiss Federal Laboratories for Materials Science and Technology, Feuerwerkerstrasse 39, Thun CH-3602, Switzerland

${ }^{3}$ Institut Jean Lamour, UMR CNRS 7198, Université de Lorraine, 2, allée André Guigné, 54000 Nancy, France

* Corresponding author. Tel.: +33 372749115.

E-mail address: sophie.legeai@ univ-lorraine.fr (S. Legeai).

\section{$\underline{\text { Abstract }}$}

Te-Bi core-shell nanowires were synthesized by electrochemical deposition in ionic liquids without using a template. The nanowires were synthesized in two steps: self-standing single crystal Te nanowires with a diameter of $76.2 \pm 28.4 \mathrm{~nm}$ and a length of a few microns were electrodeposited first, taking advantage of the templating properties of the mixture of ionic liquids EOPipTFSI:EOPipBr 95:5 mole\%. The Bi shell was then deposited on the Te core in EOPipTFSI. The influence of various experimental parameters on Bi shell deposition was studied. Thanks to the higher viscosity of the electrolyte compared to an aqueous medium, a lower growth rate is observed, leading to a thin layer of bismuth. In addition, High Resolution Transmission Electronic Microscopy shows that under optimal conditions the Te nanowires are entirely covered by a homogeneous, compact and polycrystalline $\mathrm{Bi}$ shell and that the core/shell interface is smooth.

\section{$\underline{\text { Keywords: }}$}

Core-shell nanowires, Ionic liquid, Electrodeposition, Bismuth, Tellurium 


\section{Introduction}

Tellurium exhibits outstanding thermoelectric properties and has a high Seebeck coefficient $\left(500 \mu \mathrm{V} \cdot \mathrm{K}^{-1}[1]\right)$. However its thermal conductivity is high $\left(\approx 3 \mathrm{~W} \cdot \mathrm{m}^{-1} \cdot \mathrm{K}^{-1}[2]\right)$, leading to low thermoelectric efficiency. Nanostructuring, especially the formation of nanowires, is an effective way for decreasing the lattice thermal conductivity by increasing the diffusive phonon scattering [3]. Te nanowires are easily synthesized due to the anisotropic crystalline structure of Te, which seems to favor one-dimensional growth. However, its electrical

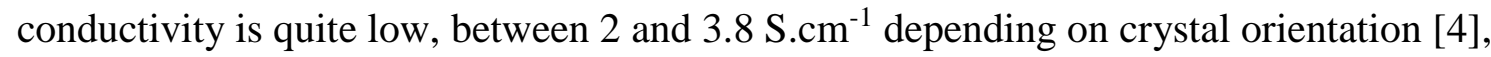
which limits its potential as a candidate for thermoelectric systems. To overcome this problem, advanced nanostructures, such as core-shell nanowires with a Te core capped by an electrical conducting shell eg of bismuth $\left(\sigma_{B i}=6.25 .10^{3} \mathrm{~S} . \mathrm{cm}^{-1}[5]\right)$ are proposed as one possible way of improving the electronic properties of the 1D material. Indeed, compared to conventional nanowires, core-shell nanostructures permit combination of the electronic properties of the materials involved and also further decrease the lattice thermal conductivity by interface phonon scattering [6]. Thus, the synthesis of core-shell structures based on Te nanowires capped by a Bi shell should lead to an interesting thermoelectric material with a very low lattice thermal conductivity, a high Seebeck coefficient and high electrical conductivity.

Te-Bi nanowires have already been synthesized by Zhang et al. using a two-step phase solution method [6]. However, in this case the Bi shell does not completely cover the surface of the nanowires and presents a rough surface with saw-like edges. In contrast, electrodeposition is a coating process which produces a homogeneous covering layer. $\mathrm{Bi}$ electrodeposition is usually performed in aqueous media [7-10]. However, $\mathrm{Bi}^{\mathrm{III}}$ precursor dissolution requires an acidic medium which could corrode the Te nanowires. An alternative is to use an ionic liquid electrolyte. As the viscosity of ionic liquids is very high (typically > $50 \mathrm{mPa} . \mathrm{s}$ at $25^{\circ} \mathrm{C}$ ), the resulting deposition rate is also slower than in aqueous media and hence more favourable to the production of thin, homogeneous layers on complex structures such as nanowire arrays [11].

Few works deal with Bi electrodeposition using ionic liquids. In an imidazolium-based ionic liquid, a Bi thin layer was obtained by underpotential deposition (UPD) on a gold substrate $[12,13]$ by electrochemical reduction of $\mathrm{Bi}^{\mathrm{III}}$ adsorbed species. On scanning towards more negative potentials, over-potential deposition (OPD) occurs, and the morphology of the Bi deposit varies from a needle-like structure to a monolayer/thin film [13]. Deep eutectic 
solvents, consisting in a melt of choline chloride with oxalic acid [14] or malonic acid [15], have also been used to deposit $\mathrm{Bi}$.

This article reports the fabrication of Te-Bi core-shell nanowires by two-step electrochemical deposition in piperidinium-based ionic liquids. The first step involves the template-free electrodeposition of single crystal Te nanowires in a binary mixture of 1-ethyl-1-octylpiperidinium bis(trifluoromethylsulfonyl)imide and 1-ethyl-1-octyl-piperidinium bromide (EOPipTFSI:EOPipBr, 95:5 mole\%). The second step concerns the electrodeposition of a Bi thin film on the Te nanowires, leading to core-shell Te-Bi nanostructures. The electrochemical behaviour of the $\mathrm{Bi}^{\mathrm{III} / \mathrm{Bi}^{0}}$ system in EOPipTFSI ionic liquid appears quite complex and exhibits several $\mathrm{Bi}^{\mathrm{III}}$ to $\mathrm{Bi}^{0}$ reduction signals. The influence of various experimental parameters on Bi shell deposition was studied: these included applied potential, $\mathrm{Bi}^{\mathrm{III}}$ concentration, density of Te nanowires and applied coulometric charge.

\section{Material and methods}

The electrochemical experiments were performed in a glove box (MBraun Labstar, $\mathrm{O}_{2} / \mathrm{H}_{2} \mathrm{O}$ levels < $1 \mathrm{ppm}$ ) using a Biologic potentiostat (VSP300). Platinum-coated glass slides (Applications Couches Minces ACM, 25×10×1 mm, Pt coating thickness $300 \mathrm{~nm}$ ) were used as working and counter electrodes in the electrodeposition experiments, while a Pt wire was used as a quasi-reference electrode (QRE).

The Te-Bi core-shell nanowires were synthesized using a two-step procedure. First, single crystalline Te nanowires were obtained using $\mathrm{TeCl}_{4}$ (99\%, Alfa Aesar) at a concentration of either 5 or $20 \mathrm{mM}$ in EOPipTFSI:EOPipBr 95:5 mole\%, as reported in a previous work [16]. Te-Bi core-shell nanowires were then obtained by electrodepositing a thin Bi film on the Te nanowires. The EOPipTFSI ionic liquid was used as the electrolyte and $\mathrm{BiBr}_{3}(99 \%$, Alfa Aesar) as the $\mathrm{Bi}^{\mathrm{III}}$ precursor. All the ionic liquids used in this work were synthesized and purified according to a previously published procedure [16].

The Te-Bi nanowires were washed several times with acetone and dried before characterization by scanning electron microscopy (SEM, Philips XL30 S FEG, 5 kV) and transmission electron microscopy (TEM, JEM-ARM 200F Cold Field Emission Gun, 200 kV, point resolution $0.19 \mathrm{~nm}$ in TEM mode) fitted with a GIF Quantum ER. The direction of growth of the nanostructures was determined by selected area electron diffraction (SAED).

\section{Results and Discussion}

\subsection{Electrodeposition of Te nanowires in an ionic liquid}


Te nanowires were obtained in EOPipTFSI:EOPipBr 95:5 mole\% by applying a constant potential corresponding to $\mathrm{Te}^{\mathrm{IV}}$ reduction. Figure 1 shows $\mathrm{SEM}$ images of the deposits obtained for two different $\mathrm{Te}^{\mathrm{IV}}$ concentrations. The nanowires are self-standing single crystals with a growth axis along the [001] direction. As shown previously [17], the density of the nanowires increases with $\left[\mathrm{Te}^{\mathrm{IV}}\right]$. Nanowires synthesized for $\left[\mathrm{Te}^{\mathrm{IV}}\right]=5 \mathrm{mM}$ (Figure 1a) have a mean length of $1.70 \pm 0.15 \mu \mathrm{m}$ and most of them have a diameter between 50 and $100 \mathrm{~nm}$ with an average of $83 \pm 37 \mathrm{~nm}$. When the Te concentration is increased to $20 \mathrm{mM}$ (Figure $1 \mathrm{~b}$ ), the deposit is denser and is composed of nanowires that are $1.0 \pm 0.1 \mu \mathrm{m}$ in length and have quite similar diameters, mostly around $140 \pm 20 \mathrm{~nm}$.

Figure 1: SEM images of Te nanowires obtained in EOPipTFSI:EOPipBr 95:5 mole\% for $\left[\mathrm{Te}^{\mathrm{IV}}\right]=$ (a) $5 \mathrm{mM}$ and (b) $20 \mathrm{mM}$. The corresponding histograms show the distribution of diameters of the nanowires.

In order to deposit $\mathrm{Bi}$ on the Te nanowires, the cathodic behaviour of $\mathrm{Bi}^{\mathrm{III}}$ in EOPipTFSI ionic liquid was studied on Pt-coated glass slides with and without Te nanowires. Linear sweep voltammograms obtained on Pt and Te working electrodes are shown in Figure 2.

Figure 2: Linear sweep voltammograms showing the electrochemical cathodic behaviour of $\mathrm{Bi}^{\mathrm{III}}$ in EOPipTFSI on Pt-coated glass slides with and without Te nanowires (synthesized using $\left.\mathrm{Te}^{\mathrm{IV}}=5 \mathrm{mM}\right) .\left[\mathrm{Bi}^{\mathrm{III}}\right]=5 \mathrm{mM}, \mathrm{T}=100^{\circ} \mathrm{C}, 5 \mathrm{mV} \cdot \mathrm{s}^{-1}$.

Whatever the substrate, three reduction peaks are observed, at $-0.49 \mathrm{~V}\left(\mathrm{C}_{1}\right),-0.70 \mathrm{~V}\left(\mathrm{C}_{2}\right)$ and $-0.99 \mathrm{~V}\left(\mathrm{C}_{3}\right)$ vs Pt, which appear before the reduction of $\mathrm{Te}^{0}$ to $\mathrm{Te}^{-\mathrm{II}}$ at $-1.5 \mathrm{~V}$ [18]. These signals all correspond to $\mathrm{Bi}^{0}$ deposition, as confirmed by XRD analysis (not shown here). The electrochemical behaviour of $\mathrm{Bi}^{\mathrm{III}}$ is the same as that observed by Fu et al. in tetrafluoroborate medium [12] but is totally different to what was observed by Szymczak et al. in EOPipTFSI:EOPipBr 95:5 mole\% [19] and in DESs [14,15]. Indeed, only one reduction peak is observed in these halide-rich media. As in the case of Te [17], In [20] and Ta [21] electrochemical systems, the low amount of halides in the TFSI-based ionic liquid leads to complex cathodic behaviour. As previously suggested in the literature [17,20], this could be due to the reduction of successive $\mathrm{BiBr}_{x}^{3-x}$ complexes to $\mathrm{Bi}^{0}$ during the potential scan. The low mass transport rate during the formation of the $\mathrm{Bi}^{0}$ deposit, due to the high viscosity of the ionic liquid $\left(\eta=15 \mathrm{mPa} . \mathrm{s}\right.$ at $\left.100^{\circ} \mathrm{C}[19]\right)$, could favour an increase in the concentration of halide ions in the vicinity of the electrode and thus modify the $\left[\mathrm{Br}^{-}\right] /\left[\mathrm{Bi}^{3+}\right]$ concentration ratios at the electrode/electrolyte interface. Successive $\mathrm{BiBr}_{x}^{3-x}$ complexes could then be formed, 
leading to multiple cathodic signals corresponding to their successive reduction. The $\mathrm{C}_{1}$ peak would thus correspond to the reduction of $\mathrm{BiBr}_{3}$ into $\mathrm{Bi}^{0}$ regardless of halide content and the later signals to the higher halide complex reductions outlined below:

$$
\begin{aligned}
& \mathrm{BiBr}_{3}+3 \mathrm{e}^{-} \rightarrow \mathrm{Bi}^{0}+3 \mathrm{Br}^{-} \\
& \mathrm{BiBr}_{4}^{-}+3 \mathrm{e}^{-} \rightarrow \mathrm{Bi}^{0}+4 \mathrm{Br}^{-} \\
& \mathrm{BiBr}_{5}^{2-}+3 \mathrm{e}^{-} \rightarrow \mathrm{Bi}^{0}+5 \mathrm{Br}^{-}
\end{aligned}
$$

\subsection{Electrodeposition of $\mathrm{Bi}$ on Te nanowires}

Bismuth was electrodeposited on Te nanowires under different experimental conditions, using a coulometric charge of $50 \mathrm{mC} / \mathrm{cm}^{2}$. The influence of the deposition potential was studied by applying different values, namely the $\mathrm{C}_{1}, \mathrm{C}_{2}$ and $\mathrm{C}_{3}$ peak potentials. The corresponding SEM images are given in Figures $3 \mathrm{a}, 3 \mathrm{~b}$ and $3 \mathrm{c}$, respectively. The influence of $\mathrm{Bi}^{\mathrm{III}}$ concentration can be seen in Figures $3 \mathrm{a}\left(\left[\mathrm{Bi}^{\mathrm{III}}\right]=5 \mathrm{mM}\right)$ and $3 \mathrm{e}\left(\left[\mathrm{Bi}^{\mathrm{III}}\right]=10 \mathrm{mM}\right)$, which show SEM images of deposits obtained at $\mathrm{C}_{1}$ peak potential. On comparing the SEM images, it seems that the highest current densities, corresponding to high overpotential values $\left(\mathrm{C}_{2}-\right.$ Figure $3 \mathrm{~b}$, and $\mathrm{C}_{3}-$ Figure $3 \mathrm{c})$, and the highest $\mathrm{Bi}^{\mathrm{III}}$ concentration $(10 \mathrm{mM}-$ Figure $3 \mathrm{e})$ lead to preferential deposition on top of the Te nanowires. By contrast, for the lowest overpotential, $\mathrm{C}_{1}$, and the lowest $\mathrm{Bi}^{\mathrm{III}}$ concentration (Figure $3 \mathrm{a}$ ), the deposit is rough but homogeneous and is composed of sheets surrounding the Te nanowires, as confirmed by TEM. It thus appears that, at higher growth rates, bismuth preferentially deposits on top of the nanowires, probably because of the highly anisotropic crystalline structure of tellurium [22].

Figure 3: SEM images of Te nanowires after Bi deposition in EOPipTFSI. Te nanowires synthesized at $\left[\mathrm{Te}^{\mathrm{IV}}\right]=5 \mathrm{mM}$, Bi deposition at the peak potentials: (a) $\mathrm{C}_{1}$, (b) $\mathrm{C}_{2}$ and (c) $\mathrm{C}_{3}$. The inset of Figure 3(a) represents a TEM image of a single nanowire. $\left[\mathrm{Bi}^{\mathrm{III}}\right]=5 \mathrm{mM}, \mathrm{Q}=50$ $\mathrm{mC} / \mathrm{cm}^{2}, \mathrm{~T}=100^{\circ} \mathrm{C}$. Te nanowires synthesized at $\left[\mathrm{Te}^{\mathrm{IV}}\right]=20 \mathrm{mM}$, Bi deposition at $\mathrm{C}_{1}$ peak potential for $\left[\mathrm{Bi}^{\mathrm{III}}\right]=$ (d) $5 \mathrm{mM}$ and (e) $10 \mathrm{mM} . \mathrm{Q}=50 \mathrm{mC} / \mathrm{cm}^{2}, \mathrm{~T}=100^{\circ} \mathrm{C}$.

Finally, the influence of the density of Te nanowires on Bi deposits obtained at $\mathrm{C}_{1}$ peak potential and for $\left[\mathrm{Bi}^{\mathrm{III}}\right]=5 \mathrm{mM}$ can be observed by comparing the SEM images in Figures $3 \mathrm{a}$ (low density of Te NWs as shown in Figure 1a) and 3d (high density of Te NWs as shown in Figure 1b). It should be noted that when the density of tellurium nanowires is high, the nanostructures are interconnected by the deposited bismuth. So in this case, no individual core-shell nanowires are obtained (Figure 3d). However, by applying low growth rate 
conditions and using substrates with a low density of Te nanowires, a smooth bismuth shell is obtained on decreasing the coulometric charge down to $16 \mathrm{mC} / \mathrm{cm}^{2}$ (Figure 4).

Figure 4: Morphological and structural analyses of Te-Bi core-shell nanowires: (a) SEM image of Te-Bi core-shell nanowires obtained after Bi electrodeposition on Te nanowires (Figure 1a type) at $\mathrm{C}_{1}$ peak potential in EOPipTFSI (inset shows the corresponding TEM image of a single nanowire); (b) histogram showing the diameter distribution of the core-shell nanowires; (c) Te-Bi interface with the corresponding Fast Fourier Transform of the Te core and the Bi shell; (d) EDX-mapping of Bi (yellow) and Te (green). $\left[\mathrm{Bi}^{\mathrm{III}}\right]=5 \mathrm{mM}, \mathrm{Q}=16$ $\mathrm{mC} / \mathrm{cm}^{2}, \mathrm{~T}=100^{\circ} \mathrm{C}$.

The Bi deposit is homogeneously deposited around the Te nanowires (Figure 4a). The statistical analysis presented in Figure $4 \mathrm{~b}$ shows that most of the nanowires have a diameter of between 75 and $125 \mathrm{~nm}$ with an average of $125.5 \pm 37.0 \mathrm{~nm}$; this is an increase of $42 \mathrm{~nm}$ compared to the initial diameter of the Te nanowires (Figure 1a). This is in accordance with the HRTEM analysis of Figure 4c. Indeed, the cross-sectional view confirms that the Bi deposit is homogeneous along the Te nanowires with a smooth interface and a thickness of around $20 \mathrm{~nm}$ (Figure 4, $\mathrm{c}$ and d). The Te and Bi crystallographic structures are highlighted in the Fast Fourier Transform images (Figure 4c). It appears that the bismuth shell is present as a polycrystalline phase whereas the Te core is a single crystal with a growth direction along the c-axis.

\section{Conclusion}

In this work, we have shown that it is possible to synthesize Te-Bi core-shell nanowires by a two-step electrodeposition procedure in ionic liquids. By optimizing the synthesis parameters, a homogeneous polycrystalline Bi layer $20 \mathrm{~nm}$ thick was deposited around Te nanowires of diameter $83.2 \pm 36.9 \mathrm{~nm}$. These nanostructures are promising materials for thermoelectric applications.

\section{$\underline{\text { References }}$}

[1] P. Bodiul, N. Bondarchuk, T. Huber, L. Konopko, A. Nikolaeva, O. Botnari, IEEE, Thermoelectric properties of films and monocrystalline whiskers of tellurium, ICT06: XXV International Conference on Thermoelectrics, Proceedings (2006) 607-610.

[2] A.P. Goncalves, E.B. Lopes, E. Alves, N.P. Barradas, N. Franco, O. Rouleau, C. Godart, New Approaches to Thermoelectric Materials, in: V. Zlatic, A.C. Hewson (Eds.) Properties 
and Applications of Thermoelectric Materials: The Search for New Materials for Thermoelectric Devices, 2009, 51-67.

[3] O. Caballero-Calero, M. Martin-González, Thermoelectric nanowires: A brief prospective, Scripta Materialia, 111 (2016) 54-57.

[4] A.S. Epstein, H. Fritzsche, K. Lark-Horovitz, Electrical properties of tellurium at the melting point and in the liquid state, Physical Review, 107 (1957) 412-419.

[5] L. Cheng, H.J. Liu, X.J. Tan, J. Zhang, J. Wei, H.Y. Lv, J. Shi, X.F. Tang, Thermoelectric properties of a monolayer bismuth, Journal of Physical Chemistry C, 118 (2014) 904-910.

[6] G.Q. Zhang, W. Wang, X.G. Li, Enhanced Thermoelectric properties of core/shell heterostructure nanowire composites, Advanced Materials, 20 (2008) 3654-3656.

[7] N.P. Osipovich, E.A. Streltsov, A.S. Susha, Bismuth underpotential deposition on tellurium, Electrochemistry Communications, 2 (2000) 822-826.

[8] W. Zhu, J.Y. Yang, X.H. Gao, J. Hou, S.Q. Bao, X.A. Fan, The underpotential deposition of bismuth and tellurium on cold rolled silver substrate by ECALE, Electrochimica Acta, 50 (2005) 5465-5472.

[9] J. Schoenleber, N. Stein, C. Boulanger, Influence of tartaric acid on diffusion coefficients of $\mathrm{Bi}^{\mathrm{III}}, \mathrm{Sb}^{\mathrm{III}}, \mathrm{Te}^{\mathrm{IV}}$ in aqueous medium: Application of electrodeposition of thermoelectric films, Journal of Electroanalytical Chemistry, 724 (2014) 111-117.

[10] A. Ananthi, S.S. Kumar, K.L. Phani, Facile one-step direct electrodeposition of bismuth nanowires on glassy carbon electrode for selective determination of folic acid, Electrochimica Acta, 151 (2015) 584-590.

[11] F. Endres, D.R. MacFarlane A. Abbott (Eds.), Electrodeposition from Ionic Liquids, WILEY-VCH, Weinheim 2008.

[12] Y.C. Fu, Y.Z. Su, H.M. Zhang, J.W. Yan, Z.X. Xie, B.W. Mao, An in situ scanning tunneling microscopic study of electrodeposition of bismuth on $\mathrm{Au}(111)$ in a 1-butyl-3methylimidazolium tetrafluoroborate ionic liquid. Precursor adsorption and underpotential deposition, Electrochimica Acta, 55 (2010) 8105-8110.

[13] G.B. Pan, W. Freyland, Electrocrystallization of Bi on $\mathrm{Au}(111)$ in an acidic chloroaluminate ionic liquid, Electrochimica Acta, 52 (2007) 7254-7261. 
[14] C. Agapescu, A. Cojocaru, A. Cotarta, T. Visan, Electrodeposition of bismuth, tellurium, and bismuth telluride thin films from choline chloride-oxalic acid ionic liquid, Journal of Applied Electrochemistry, 43 (2013) 309-321.

[15] F. Golgovici, T. Visan, Electrochemical deposition of BiTe films from choline chloridemalonic acid mixture as ionic liquid, Chalcogenide Letters, 9 (2012) 427-434.

[16] L. Thiebaud, S. Legeai, N. Stein, Tuning the morphology of Te one-dimensional nanostructures by template-free electrochemical deposition in an ionic liquid, Electrochimica Acta, 197 (2016) 300-306.

[17] L. Thiebaud, S. Legeai, J. Ghanbaja, N. Stein, Electrodeposition of high aspect ratio single crystalline tellurium nanowires from piperidinium-based ionic liquid, Electrochimica Acta, 222 (2016) 528-534.

[18] E.G.S. Jeng, I.W. Sun, Electrochemistry of tellurium(IV) in the basic aluminum chloride1-methyl-3-ethylimidazolium chloride room temperature molten salt, Journal of the Electrochemical Society, 144 (1997) 2369-2374.

[19] J. Szymczak, S. Legeai, S. Michel, S. Diliberto, N. Stein, C. Boulanger,

Electrodeposition of stoichiometric bismuth telluride $\mathrm{Bi}_{2} \mathrm{Te}_{3}$ using a piperidinium ionic liquid binary mixture, Electrochimica Acta, 137 (2014) 586-594.

[20] Y. Traore, S. Legeai, S. Diliberto, G. Arrachart, S. Pellet-Rostaing, M. Draye, New insight into indium electrochemistry in a $\mathrm{Tf}_{2} \mathrm{~N}$-based room-temperature ionic liquid, Electrochimica Acta, 58 (2011) 532-540.

[21] N. Borisenko, A. Ispas, E. Zschippang, Q. Liu, S.Z. El Abedin, A. Bund, F. Endres, In situ STM and EQCM studies of tantalum electrodeposition from $\mathrm{TaF}_{5}$ in the air- and waterstable ionic liquid 1-butyl-1-methylpyrrolidinium bis(trifluoromethylsulfonyl)amide, Electrochimica Acta, 54 (2009) 1519-1528.

[22] H.H. Li, P. Zhang, C.L. Liang, J. Yang, M. Zhou, X.H. Lu, G.A. Hope, Facile electrochemical synthesis of tellurium nanorods and their photoconductive properties, Crystal Research and Technology, 47 (2012) 1069-1074. 